\title{
AVALIAÇÃO DA QUALIDADE MICROBIOLÓGICA DE QUEIJOS COLONIAIS COMERCIALIZADOS EM FEIRA LIVRE NA CIDADE DE FRAIBURGO, SC
}

Evaluation of the microbiological quality of colonial cheeses sold at open air market in Fraiburgo, SC

https://doi.org/10.18593/eba.28120

Recebido em 19 de julho de 2021. Aceito em 21 de setembro de 2021.

\section{Stefanie Manoela Paim*®i] César Milton Barattot@@}

\begin{abstract}
Graduanda em Biotecnologia Industrial pela Universidade do Oeste de Santa Catarina de Videira.
Pós-Doutor Empresarial pela Empresa Bioplus Desenvolvimento Biotecnológico Ltda; Doutor em Biologia Celular e Molecular pela Universidade Federal do Rio Grande do Sul; Mestre em Biologia Celular e Molecular pela Universidade Federal do Rio Grande do Sul; Coordenador do Curso de bacharelado em Biotecnologia Industrial; Professor e Pesquisador na Universidade do Oeste de Santa Catarina de Videira.
\end{abstract}

Resumo: O queijo colonial de leite cru é um produto artesanal geralmente comercializado em feiras livres. Portanto, além das condições instáveis de produção, existem outras variantes que afetam sua qualidade sanitária até chegar ao ponto de venda. Devido ao risco potencial de doenças transmitidas por alimentos, o risco de contaminação microbiana é alto, assim o comércio informal de leite e produtos lácteos tem efeitos relacionados na saúde pública. O presente trabalho teve como objetivo avaliar a qualidade microbiológica de queijos coloniais comercializados em feira livre na cidade de Fraiburgo/SC, de forma a verificar se tais produtos obedecem aos parâmetros exigidos na legislação vigente. Durante o período de seis meses (de novembro de 2020 a abril de 2021), foram coletadas mensalmente três amostras de queijo colonial adquiridos em três diferentes produtores na feira livre do município de Fraiburgo, localizado no Meio-Oeste de Santa Catarina. Após coletadas, as amostras foram conduzidas até o setor microbiológico do Laboratório Terranálises (Fraiburgo/SC), onde foram realizadas as análises de Escherichia coli (E. coli), contagem de estafilococos coagulase positiva e pesquisa de Salmonella spp. Com base nos resultados obtidos pode-se afirmar que as 38,89\% (7/18) das amostras de queijo colonial não se encontram em acordo com os padrões microbiológicos legais vigentes, sendo que $27,78 \%$ (5/18) das amostras estavam em não-conformidade com o padrão de E. coli e 33,3\% (6/18) não estavam conforme com o limite máximo aceito para estafilococos coagulase positiva. Contudo, nenhuma das amostras obteve presença para Salmonella spp. Assim, é necessário investir no uso adequado de boas práticas de fabricação em tais produtos, bem como fiscalizar as feiras livres para obediência às normas sanitárias na manipulação higiênica dos alimentos, e capacitar os produtores em relação a forma correta de armazenamento e transporte de seus produtos, para assim garantir sua qualidade desde o campo até a venda ao consumidor.

Palavras-chave: Contaminação. Salmonella. Escherichia coli. Estafilococos. 
Abstract: The colonial raw milk cheese is a handmade product usually sold at open air markets. Thus, in addition to unstable production conditions, there are other variants that affect its sanitary quality until it reaches the point of sale. Due to the potential risk of foodborne illnesses, the risk of microbial contamination is high, so informal trade in milk and dairy products has related effects on public health. This study aimed to evaluate the microbiological quality of colonial cheeses sold in open air markets in the city of Fraiburgo/SC, in order to verify whether such products comply with the parameters required by current legislation. During a six-month period (November 2020 to April 2021), three samples of colonial cheese purchased from three different producers were collected monthly at the open air market in Fraiburgo, located in the Midwest of Santa Catarina. After being collected, the samples were taken to the microbiological laboratory of the Laboratório Terranálises (Fraiburgo/SC), where the analysis of enumeration of Escherichia coli, enumeration of coagulase-positive staphylococci and investigation of Salmonella spp. Based on the results obtained, it can be stated that 38.89\% (7/18) of the colonial cheese samples are not in accordance with the current legal microbiological standards, with $27.78 \%$ (5/18) of the samples were in non-compliance with the Escherichia coli standard and 33.3\% (6/18) were not in compliance with the accepted upper limit for coagulasepositive staphylococci. However, none of the samples were contaminated with Salmonella spp. Thus, it is necessary to invest in the proper use of good manufacturing practices in such products, as well as inspect open air markets to comply with sanitary standards in the hygienic handling of food, and train producers in relation to the correct way to store and transport their products in order to ensure its quality from the field to the sale to the purchaser. Keywords: Contamination. Salmonella. Escherichia coli. staphylococci.

\section{INTRODUÇÃO}

O queijo é um alimento nutritivo amplamente aceito e consumido por pessoas de todos os níveis sociais e idades ${ }^{1}$. O queijo colonial de leite cru é um produto artesanal obtido a partir da separação do soro de leite, e foi originado de imigrantes europeus que se estabeleceram ao sul do Brasil, levando métodos, técnicas e tradições artesanais ${ }^{2}$.

No Brasil, existem queijos tradicionais feitos com leite cru em diversas regiões, geralmente produzidos em pequena escala na agricultura familiar e nos pequenos produtores, como o queijo Colonial, no sul do Brasil. Esses produtos possuem atrativos únicos e variam de acordo com as diferentes regiões nas quais foram fabricados, sendo difícil padronizá-los3.

Atualmente, essetipo dequeijoéproduzido a partir do leite pasteurizado em pequenas e médias fábricas de laticínios. De acordo com o Sistema de Informação Gerencial da Inspeção Federal do Ministério da Agricultura, Pecuária e
Abastecimento (MAPA), entre 2010 e 2014, Paraná, Santa Catarina e Rio Grande do Sul produziram mais de 7,1 mil toneladas de queijo colonial, sob fiscalização federal ${ }^{4}$.

Embora também seja produzido em laticínios, o queijo colonial de leite cru tem importante significado econômico para os pequenos produtores de leite, que o produzem para o consumo doméstico e vendem o excedente para aumentar a renda familiar e garantir sua permanência no campo $^{2}$. Esses produtos geralmente são comercializados em feiras livres. Portanto, além das condições instáveis de produção, existem outras variantes, como as más condições de armazenamento e transporte, que afetam sua qualidade sanitária até chegar ao ponto de venda. Quanto a estes, a situação é ainda pior, porque estão expostos a estruturas externas, onde não existeequipamento de refrigeração, nemabrigo da luz solar. Em alguns desses casos, o vendedor manipula o produto enquanto está em contato com o dinheiro. As vendas e fracionamento são feitos inteiramente à mão, de forma que produtores e 
comerciantes são privados de equipamentos de proteção individual e coletiva 5 .

Devido ao risco potencial de doenças transmitidas por alimentos (DTA), o risco de contaminação microbiana é alto, o que é de grande importância para a saúde pública. Desse ponto de vista, as pessoas devem obter alimentos de alta qualidade dentro do seu âmbito e dentro dos padrões estabelecidos, não só em termos de valor nutricional, mas também em termos de condições higiênicas para garantir a saúde dos consumidores 5 .

Entre os produtos lácteos, os queijos artesanais são considerados os portadores mais comuns de patógenos, pois são produzidos principalmente a partir de leite não pasteurizado. Devido ao risco de propagação de doenças de origem alimentar, o comércio informal de leite e produtos lácteos tem efeitos relacionados na saúde pública ${ }^{6}$.

A presença de patógenos em produtos lácteos tornou-se um grande problema de saúde pública. A ingestão de queijo contaminado pode causar muitas doenças, desde zoonoses (brucelose, tuberculose) até intoxicações alimentares. Assim, queijos produzidos com leite cru ou queijos produzidos em más condições sanitárias podem não ser adequados para consumo ${ }^{7-8}$.

Diante do exposto e levando em consideração os riscos microbiológicos à saúde pública, o presente trabalho teve como objetivo avaliar a qualidade microbiológica de queijos coloniais comercializados em feira livre na cidade de Fraiburgo/SC, de forma a verificar se tais produtos obedecem aos parâmetros exigidos na legislação vigente.

\section{MATERIAL E MÉTODOS}

Durante o período de seis meses (de novembro de 2020 a abril de 2021), foram coletadas mensalmente três amostras de queijo colonial adquiridos em três diferentes produtores na feira livre do município de Fraiburgo, localizado no Meio-Oeste de Santa Catarina. As amostras foram coletadas na qualidade de consumidor e, imediatamente após aquisição, foram identificadas, acondicionadas em caixa térmica com gelo reciclável e levadas até o setor microbiológico do Laboratório Terranálises (Fraiburgo/SC), onde foram realizadas as análises.

As análises microbiológicas realizadas foram contagem de Escherichia coli (E. coli), contagem de estafilococos coagulase positiva e pesquisa de Salmonella spp. Os procedimentos utilizados para tais análises foram previamente validados pelo laboratório.

As unidades analíticas (25 g de queijo) foram coletadas a partir da unidade amostral em capela de fluxo laminar vertical, com o auxílio de bisturis e pinças estéreis. Após a remoção da camada externa de um dos lados do queijo, foram colhidas porções de diferentes pontos da matriz, transferindo-as diretamente para sacos de amostragem estéreis até que se completassem as $\mathbf{2 5}$ g necessárias aos procedimentos analíticos. Entre cada amostra processada, era realizada a higienização da capela e da balança com álcool $70 \%$, bem como a esterilização de bisturis e pinças em esterilizador elétrico.

A detecção de Salmonella spp. foi realizada de acordo com metodologia descrita na ISO 6579-1:20179 ${ }^{9}$ compreendendo as etapas de préenriquecimento, na qual alíquotas de $25 \mathrm{~g}$ de queijo foram adicionadas a $225 \mathrm{~mL}$ de água peptonada 
tamponada $1 \%$ e incubadas a $37{ }^{\circ} \mathrm{C}$ durante $18-20$ h; e enriquecimento seletivo no qual alíquotas de o,1 $\mathrm{mL}$ do pré-enriquecimento foram inoculadas em $10 \mathrm{~mL}$ de caldo Rappaport-Vassiliadis (RVS) incubados a $41,5{ }^{\circ} \mathrm{C}$ por $18-24 \mathrm{~h}$. Paralelamente, alíquotas de $1 \mathrm{~mL}$ do pré-enriquecimento foram inoculadas em $10 \mathrm{~mL}$ de caldo Muller-Kauffmann Tetrationato Novobiocina (MKTTn) e incubados a $37^{\circ} \mathrm{C}$ durante 18-24 h. Após a incubação, realizouse o isolamento em meios sólidos seletivos nos quais foram estriados os inóculos provenientes dos caldos de enriquecimento seletivo em ágar Verde Brilhante (VBA) e ágar XLD, ambos incubados a $37^{\circ} \mathrm{C}$ durante $24 \mathrm{~h}$. As colônias suspeitas de Salmonella spp. foram semeadas nos seguintes testes bioquímicos: ureia, tríplice açúcar e ferro e lisina descarboxilase.

A enumeração de $E$. coli foi conduzida de acordo com a ISO 16649-2: 2001 ${ }^{10}$. Alíquotas de $25 \mathrm{~g}$ de queijo foram adicionadas a $225 \mathrm{~mL}$ de água peptonada a $0,1 \%$. A partir dessa primeira diluição $\left(10^{-1}\right)$ foram realizadas diluições decimais seriadas até $10^{-5}$. Posteriormente, $1,0 \mathrm{~mL}$ de cada diluição foi inoculado em placas de Petri estéreis vazias. Foram adicionados de 15 a $20 \mathrm{~mL}$ de ágar TBX previamente fundido e resfriado a $44^{-4} 7^{\circ} \mathrm{C}$ em cada placa de Petri previamente inoculada. As placas foram homogeneizadas em forma de oito e, após a solidificação do ágar, incubadas a $44^{\circ} \mathrm{C}$ por $24 \mathrm{~h}$. Após esse período foram realizadas as contagens das Unidades Formadoras de Colônias por grama (UFC/g).

A contagem de estafilococos coagulase positiva foi realizada com base no documento ABNT NBR ISO 6888-1:2019". Alíquotas de 25 $\mathrm{g}$ de queijo foram adicionadas a $225 \mathrm{~mL}$ de água peptonada a $0,1 \%$. A partir dessa diluição $\left(10^{-1}\right)$, foram realizadas diluições decimais seriadas até
$10^{-5}$. Posteriormente, $1,0 \mathrm{~mL}$ de cada diluição foi semeado, pela técnica de inoculação em superfície, em três placas de Petri de ágar Baird-Parker (BP) incubadasa $35^{\circ} \mathrm{C}$ durante $48 \mathrm{~h}$. Após este período foi realizada as contagens das Unidades Formadoras de Colônias por grama (UFC/g) de amostra em placas contendo no máximo 300 colônias (150 colônias típicas e/ou atípicas em duas diluições sucessivas). Foram selecionadas cinco colônias típicas e cinco atípicas em ágar BP, inoculadas em caldo BHI (Brain-Heart Infusion broth) incubados a $35{ }^{\circ} \mathrm{C}$ durante $24 \mathrm{~h}$ para confirmação a partir da prova de coagulase.

\section{RESULTADOS E DISCUSSÃO}

Os resultados microbiológicos obtidos nas análises microbiológicas dos queijos coletados encontram-se na Tabela 1.

A Instrução Normativa № 6o, de 23 de dezembro de 2019, estabelece as listas de padrões microbiológicos para alimentos. Apesar das diferenças, vários estudos ${ }^{12-16}$ têm demonstrado que o teor de umidade dos queijos coloniais está entre $46 \%$ e $55 \%$, indicando que se trata de queijos com alto teor de umidade. Para tais queijos de alta umidade, os limites máximos para E. coli, estafilococos coagulase positiva e Salmonella spp. são de $1,0 \times 10^{3} \mathrm{UFC} / \mathrm{g}, 1,0 \times 10^{3} \mathrm{UFC} / \mathrm{g}$ e ausência em $25 \mathrm{~g}$, respectivamente ${ }^{17}$. 
Tabela 1 - Resultados microbiológicos obtidos nas análises de queijos coloniais comercializados em feira livre na cidade de Fraiburgo/SC.

\begin{tabular}{|c|c|c|c|}
\hline \multirow{3}{*}{ Amostra } & \multicolumn{3}{|c|}{ Valor encontrado por amostra } \\
\hline & \multicolumn{2}{|c|}{ Enumeração (UFC/g) } & \multirow{2}{*}{$\begin{array}{c}\text { Detecção (em 25g) } \\
\text { Salmonella spp. }\end{array}$} \\
\hline & Escherichia coli & Estafilococos coagulase positiva & \\
\hline $\mathrm{N}_{1}$ & $1,5 \times 10^{7 n c}$ & $4,7 \times 10^{3 \mathrm{nc}}$ & Ausência \\
\hline $\mathrm{N}_{2}$ & $8, \mathrm{oxio}^{1}$ & $3,3 \times 10^{2}$ & Ausência \\
\hline $\mathrm{N}_{3}$ & $4,9 \times 10^{5 \mathrm{nc}}$ & $8,1 \times 10^{5 \mathrm{nc}}$ & Ausência \\
\hline D1 & $3,2 \times 10^{3} \mathrm{nc}$ & $8, \mathrm{ox}_{10}^{3 \mathrm{nc}}$ & Ausência \\
\hline $\mathrm{D}_{2}$ & $1,0 \times 10^{1}$ & $<1, \mathrm{OXx10}^{1}$ & Ausência \\
\hline $\mathrm{D}_{3}$ & $5,0 \times 10^{1}$ & $3,5 \times 10^{2}$ & Ausência \\
\hline $\mathrm{J}_{1}$ & $5,4 \times 10^{4 \mathrm{nc}}$ & $2,2 \times 10^{5 \mathrm{nc}}$ & Ausência \\
\hline $\mathrm{J}_{2}$ & $1,4 \times 10^{2}$ & $3,6 \times 10^{3 \mathrm{nc}}$ & Ausência \\
\hline $\mathrm{J} 3$ & $<1, \mathrm{OXX1O}^{1}$ & $<1, \mathrm{OXX1O}^{1}$ & Ausência \\
\hline$F_{1}$ & $9,0 \times 10^{1}$ & $2,8 \times 10^{2}$ & Ausência \\
\hline $\mathrm{F}_{2}$ & $5,4 \times 10^{3 \mathrm{nc}}$ & $1,4 \times 10^{2}$ & Ausência \\
\hline $\mathrm{F}_{3}$ & $<1, \mathrm{OXX10}^{1}$ & $4,0 \times 10^{2}$ & Ausência \\
\hline M1 & $<1, \mathrm{OX1O}^{1}$ & $<1, \mathrm{OX1O}^{1}$ & Ausência \\
\hline $\mathrm{M} 2$ & $5,0 \times 10^{1}$ & $4,9 \times 10^{2}$ & Ausência \\
\hline $\mathrm{M}_{3}$ & $1,2 \times 10^{2}$ & $1,0 \times 10^{3}$ & Ausência \\
\hline A1 & $5,2 \times 10^{2}$ & $7,8 \times 10^{6 \mathrm{nc}}$ & Ausência \\
\hline $\mathrm{A} 2$ & $1,0 \times 10^{2}$ & $7,4 \times 10^{2}$ & Ausência \\
\hline $\mathrm{A}_{3}$ & $3,0 \times 10^{1}$ & $9,0 \times 10^{2}$ & Ausência \\
\hline Padrão microbiológico IN 60 & $1,0 \times 10^{3}$ & $1,0 \times 10^{3}$ & Ausência \\
\hline $\begin{array}{l}\text { Número de amostras não } \\
\text { conformes }\end{array}$ & $27,78 \%$ & $33,33 \%$ & o,o\% \\
\hline
\end{tabular}

Legenda: N=novembro, $\mathrm{D}=$ dezembro, J=janeiro, $\mathrm{F}=$ fevereiro, $\mathrm{M}=$ março, $\mathrm{A}=$ abril, nc=não-conforme.

As análises microbiológicas evidenciaram que $38,89 \% \quad(7 / 18)$ dos queijos analisados estavam não-conformes com pelo menos um dos parâmetros microbiológicos estabelecidos na legislação vigente para este alimento, portanto impróprios ao consumo humano.

Com base na contagem de E. coli (Tabela 1) encontrada nas amostras pode-se afirmar 27,78\% (5/18) dos queijos analisados não se encontraram dentro do padrão microbiológico estabelecido pela Instrução Normativa no 6o, de 23/12/2019, a qual fixa 1,ox10 3 UFC/g como tolerável para o queijo de alta umidade, como é o caso do queijo colonial.

A E. coli faz parte do grupo dos coliformes termotolerantes que, por sua vez, incluem-se nos coliformes totais. Os coliformes totais são bactérias da família Enterobacteriaceae, que podem fermentar a lactose e produzir gases a uma temperatura de 35 a $37^{\circ} \mathrm{C}$ por $48 \mathrm{~h}$. Por outro lado, os coliformes termotolerantes podem suportar temperaturas acima de $40^{\circ} \mathrm{C}$. A presença dessas bactérias indica falha de processamento ou contaminação após o processamento e, portanto, 
é um indicador geral das condições sanitárias. A presença de coliformes nos alimentos não indica necessariamentea presença de contaminação fecal, o que difere da presença de E. coli pertencente a esse grupo, e sua análise é utilizada como indicador de contaminação fecal ${ }^{18}$.

Resultado semelhante aos queijos analisados foram também encontrados por Casaril et al. ${ }^{19} \mathrm{em}$ queijo colonial, com $40 \%$ das amostras analisadas com valores de Escherichia coli fora dos parâmetros exigidos pela legislação vigente. Já no estudo de Ressutte ${ }^{20}$, $100 \%$ das amostras de queijo colonial processados com leite cru encontraramse dentro do padrão microbiológico estipulado para E. coli.

A análise microbiológica para Salmonella sp. (Tabela 1) encontrou-se dentro do padrão exigido pela legislação (IN nº 60 de 23/12/2019), sendo ausente em todos os queijos analisados. Estudos afirmam que a alta frequência de bactérias ácido-láticas (BAL), presentes no leite cru exercem atividade antagonista a Salmonella spp. ${ }^{2-}$ 23. Este resultado está de acordo com Ressutte, Tamankievies e Zampieron, Mascitti, Amaral, Lages e Zavaschi ${ }^{20,}{ }^{24-28}$ que ao analisarem queijos coloniais em seus trabalhos, também relaram ausência de Salmonella spp.

No que se refere aos estafilococos coagulase positiva, como pode ser observado na Tabela 1, 33,3\% (6/18) dos queijos analisados apresentaram contagens maiores que $10^{3} \mathrm{UFC} / \mathrm{g}$ de amostra, não se enquadrando, portanto, no padrão microbiológico estabelecido pela $\mathrm{IN} \mathrm{n}^{\circ} 60$ de 23/12/2019, a qual tolera uma contagem de até $10^{3} \mathrm{UFC} / \mathrm{g}$ de amostra para esse microrganismo.

Almeida e Franco $^{29}$ enfatizam que o Staphylococcus aureus, o maior representante do grupo dos estafilococos coagulase positiva, é um microrganismo que faz parte da microbiota da pele e da mucosa humana. A sua presença em alimentos pode ser devido a falha de processamento e/ou contaminação pós-processamento.

Em estudo realizado por Benincáso, todas as amostras de queijo colonial analisadas se apresentaram não-conformes para o consumo humano, com valores de estafilococos coagulase positiva variando entre $4,8 \times 10^{5}$ a $1,2 \times 10^{6} \mathrm{UFC} / \mathrm{g}$. Em outro estudo, Tavares et al. ${ }^{31}$ observaram que 18 das 30 amostras de queijo artesanal produzido na região sul do Rio Grande do Sul apresentaram contagem de estafilococos coagulase positiva acima de $10^{5} \mathrm{UFC} / \mathrm{g}$.

Já no trabalho apresentado por Tamankievies e Zampieron ${ }^{24}$, os queijos coloniais foram analisados no início da maturação e ao final e 60 dias, e as análises mostraram que no período inicial de maturação as contagens de estafilococos coagulase positiva estavam acima do limite aceitável. Porém no tempo final de maturação (6o dias), os resultados não indicaram contaminação por estafilococos. Assim, as autoras apontaram que a maturação é eficiente para redução deste microrganismo.

O queijo colonial é um produto artesanal de grande importância para os pequenos produtores, além de ser considerado um alimento altamente manipulado, ficando suscetível a maior contaminação, principalmente de origem microbiana. O uso adequado de boas práticas de fabricação em tais produtos é um requisito muito importante para a obtenção de alimentos seguros para consumo humano. Para tanto, é necessário investir em sua assistência técnica para fornecer informações e orientações para o aprimoramento das boas práticas de produção e higiene, além 
de métodos padronizados, para garantir que o produto final esteja em conformidade com a legislação e esteja disponível para consumo seguro.

\section{CONCLUSÃO}

Com base nos resultados obtidos podese afirmar que as 38,89\% das amostras de queijo colonial coletadas em feira livre na cidade de Fraiburgo/SC não se encontram em acordo com os padrões microbiológicos legais vigentes, sendo que $27,78 \%$ das amostras estavam em nãoconformidade com o padrão de E. coli e 33,3\% não estavam conforme com o limite máximo aceito para estafilococos coagulase positiva. Contudo, nenhuma das amostras analisadas obteve presença para Salmonella spp. Portanto, tendo em vista o risco microbiológico atrelado a tais produtos, as feiras livres devem contar com gestores capazes de realizar uma fiscalização dos setores para a obediência às normas sanitárias na manipulação higiênica dos alimentos, bem como capacitar os produtores em relação a forma correta de armazenamento e transporte de seus produtos, para assim garantir sua qualidade desde o campo até a venda ao consumidor.

\section{CONFLITOS DE INTERESSE}

Os pesquisadores afirmam que não existem conflitos de interesse.

\section{REFERÊNCIAS}

1 Silva JFQ, Filizola LRS, Maia MMD, Sena MJ. Utilização de coliformes termotolerantes como indicadores higiênico-sanitários de queijo Prato comercializado em supermercados e feiras livres de Recife PE, Brasil. Medicina Veterinária [Internet]. 2008 [acesso em 2021 maio 10]; 1(2):21-25. Disponível em: http://journals.ufrpe.br/index.php/medicinaveterinaria/article/view/713.

2 Radaelli IM, Pasinato TL. Legislação na produção e comercialização de queijo colonial de leite cru: a importância para a socioeconomia da região oeste de Santa Catarina. SIEPE [Internet]. ㄴo de setembro de 2020 [acesso em 2021 maio 10]; e25652. Disponível em: https://portalperiodicos.unoesc. edu.br/siepe/article/view/25652.

3 Carvalho MM. A agroindústria familiar rural e a produção de queijos artesanais no município de Seara, Estado de Santa Catarina - um estudo de caso [dissertação]. Marechal Cândido Rondon: Centro de Ciências Agrárias: Universidade Estadual do Oeste do Paraná; 2015. 53p.

4 Mattiello CA, Silveira SM, Carli F, Cunha Júnior A, Alessio DRM, Pelizza A et al. Rendimento industrial, eficiência de fabricação e características físico-químicas de queijo colonial produzido de leite com dois níveis de células somáticas. ArqBrasMedVetZootec. 2018; 70(6):1916-24.

5 Correia M. Características microscópicas de queijos prato, mussarela e mineiro comercializados em feiras livres da Cidade de São Paulo. Rev. Saúde Pública. 1997; 31(3):296-301. 
6 Silva Júnior ACS, Malcher EST, Silva ASS, Nascimento JF, Barroso BS. Perfil de resistência a antimicrobianos de Staphylococcus aureus isolados de queijo manteiga comercializado em feira pública da cidade de Macapá, AP. Rev. Hig. Alimentar. 2017; 31(274):115-9.

7 Sobrinho PSC, Faria CAM, Pinheiro JS, Almeida HG, Pires CV, Santos AS. Bacteriological Quality of Raw Milk Used for Production of a Brazilian Farmstead Raw Milk Cheese. Foodborne Pathogens and Disease. 2012; 9(2):138-144.

8 Leite MMD, Lima MG, Reis RB. Ocorrência de Staphylococcus aureus em queijo Minas tipo Frescal. Rev. Hig. Alimentar. 2005; 19(132):89-93.

9 International Organization for Standardization. ISO/TC 6579-1: Microbiology of the food chain - Horizontal method for the detection, enumeration and serotyping of Salmonella - Part 1: Detection of Salmonella spp. Geneva: ISO; 2017. 48 p.

10 International Organization for Standardization. ISO/TC 16649-2: Microbiology of food and animal feeding stuffs - Horizontal method for the enumeration of beta-glucuronidase-positive Escherichia coli - Part 2: Colony-count technique at 44 degrees $\mathrm{C}$ using 5-bromo-4-chloro-3-indolyl beta-D-glucuronide. Geneva: ISO; 2001. 8 p.

11 Associação Brasileira de Normas Técnicas. ABNT NBR ISO 6888-1: Microbiologia de alimentos para consumo humano e animal - Método horizontal para enumeração de estafilococos coagulase positiva (Staphylococcus aureus e outras espécies). Rio de Janeiro: ABNT; 2019. 20 p.

12 Delamare APL, Andrade CCP, Mandelli F, Almeida RC, Echeverrigaray S. Microbiological, Physico-Chemical and Sensorial Characteristics of Serrano, an Artisanal Brazilian Cheese. Food and Nutrition Sciences. 2012; 1(3):1068-75.

13 Lucas SDM, Scalco A, Feldhaus S, Drunkler DA, Colla E. Padrão de identidade e qualidade de queijos colonial e prato, comercializados na cidade de Medianeira - PR. Rev. Inst. Latic. "Cândido Tostes". 2012; 67(386):38-44.

14 Silveira Júnior JF, Oliveira DF, Braghini F, Edenes MSL, Bravo CEC, Tonial IB. Caracterização físico-química de queijos coloniais produzidos em diferentes épocas do ano. Rev. Inst. Latic. "Cândido Tostes". 2012; 67(386):67-80.

15 Cabral JS, Dias CR, Argenta NSS, Rodrigues JA, Freitas K, Guedes FF et al. Avaliação do queijo colonial da mesorregião metropolitana de Porto Alegre quanto às suas características físico-químicas. In: Anais do $3^{\circ}$ Colóquio Ulbra de Extensão, Pesquisa e Ensino. 2017 Jun 21. Canoas, Brasil.

16 Guedes F, Cardoso J, Cabral J, Bresolin B, Dias C. Caracterização físico-química do queijo colonial produzido na mesorregião do centro oriental Riograndense. In: Anais do $57^{\circ}$ Congresso Brasileiro de Química 2017 Out 23-27. Gramado, Brasil. 
17 Ministério da Saúde. Instrução Normativa n6o/2019. Estabelece as listas de padrões microbiológicos para alimentos. Diário Oficial da União. 2019 Dez 23; 249(seção 1):133.

18 Silva JG. Características físicas, físico-químicas e sensoriais de queijo de minas artesanal da Canastra [master's thesis]. Lavras: Universidade Federal de Lavras; 2007. 210 p.

19 Casaril KBPB, Bento CBP, Henning K, Pereira M, Dias VA. Qualidade microbiológica de salames e queijos coloniais produzidos e comercializados na região sudoeste do Paraná. Revista Brasileira de Agropecuária Sustentável. 2017; 7(2):77-85.

20 Ressutte JB, Stella TR, Pozza MSS, Madrona GS. Análise microbiológica de queijo tipo colonial produzido a partir de leite cru e pasteurizado. In: Anais do 6o Simpósio de Segurança Alimentar. 2018 Mai 15-18. Gramado, Brasil.

21 Nero LA, Mattos MR, Beloti V, Barros MAF, Ortolani MBT, Franco BDGM. Autochthonous Microbiota of Raw Milk With Antagonistic Activity AgainstListeria Monocytogenes and Salmonella Enteritidis. Journal of Food Safety. 2009; 29: 261-270.

22 Ribeiro JL. Potencial Tecnológico, Probiótico e Antagonista da Microbiota Lática de Leite de Búfalas [tese]. Brasília: Universidade de Brasília/ Faculdade de Agronomia e Veterinária; 2019. 109 p.

23 Melo FD, Dalmina KA, Pereira MN, Ramella MV, Neto AT, Vaz EK, Ferraz SM. Avaliação da Inocuidade e Qualidade Microbiológica do Queijo Artesanal Serrano e Sua Relação com as Variáveis Físico Químicas e o Período de Maturação. Acta Scientiae Veterinariae.2013; 41: 1-7.

24 Tamankievies GP, Zampieron M. Caracterização da maturação do queijo colonial de leite cru produzido em São Miguel do Oeste - SC [undergraduate thesis]. São Miguel do Oeste: Instituto Federal de Santa Catarina; 2019. 30 p.

25 Mascitti A, Grecellé C, Silva L, Brasil J, Lunge VR. Avaliação da qualidade microbiológica de queijos coloniais produzidos no Rio Grande do Sul. In: Anais do 23ํㅗำ de Iniciação Científica e Tecnológica. 2017. Canoas, Brasil.

26 Amaral JW, Souza SMO, Ribeiro JL, Poggiani SSC, Ferreira MA. Avaliação da qualidade de queijos de produção informal. Segur. Aliment. Nutr. 2020; 27(1):1-6.

27 Lages LZ, Gandra TKV, Alves PIC, Gandra EA. Análise microbiológica de queijos coloniais comercializados em feiras no município de Pelotas - RS, Brasil. In: Anais $4^{\text {a }}$ Semana Integrada UFPel. 2018. Pelotas, Brasil.

28 Zavaschi CD. Avaliação da qualidade de queijo colonial, mel e melado fornecidos na alimentação escolar do município de Francisco Beltrão-PR [undergraduate thesis]. Franscisco Beltrão: Universidade Tecnológica Federal do Paraná; 2016. 58 p. 
29 Almeida PMP, Franco RM. Avaliação bacteriológica de queijo tipo minas frescal com pesquisa de patógenos importantes à saúde pública: Staphylococcus aureus, Salmonella sp. e coliformes fecais. Revista Higiene Alimentar. 2003; 17(11):79-85.

30 Benincá T. Queijo colonial artesanal no vale do Taquari/RS: numa perspectiva social, sanitária e microbiológica [master's thesis]. São Francisco de Paula: Universidade Estadual do Rio Grande Do Sul; 2021. $87 \mathrm{p}$.

31 Tavares AB, Cavalcanti EANLD, Timm CD, Lima HG, Cereser ND. Queijo artesanal produzido no sul do Rio Grande do Sul: avaliação físico-química, microbiológica e suscetibilidade a antimicrobianos de isolados de Staphylococcus coagulase positiva. Ciência Animal Brasileira. 2019; 20:1-10. 